\title{
Application of Magnetic Nanoparticles with structure of Core-Shell, as bactericidal \\ Mansour Binandeh*
}

Faculty of Chemistry and Environmental Sciences, University of Maragheh, Iran.

Corresponding Author: Mansour Binandeh, Faculty of Chemistry and Environmental Sciences, University of Maragheh, Iran. Received date: April 11, 2018; Accepted date : April 25, 2018; Published date: May 03, 2018.

Citation this Article ; Mansour Binandeh, Application of Magnetic Nanoparticles with structure of Core-Shell, as bactericidal. J Immunology and Inflammation Diseases Therapy. DOI:10.31579/2637-8876/023

Copyright: (c) 2018 Mansour Binandeh. This is an open-access article distributed under the terms of The Creative Commons Attribution License, which permits unrestricted use, distribution, and reproduction in any medium, provided the original author and source are credited.

\begin{abstract}
Initially, magnetic nanoparticles (MNP) $\mathrm{Fe}_{3} \mathrm{O}_{4}$ are synthesized by a chemical correlation method and its core / shell structure is detected using SEM, FT-IR analysis. The purpose of this production was to use the nanoparticle performance level in the absorption of antibiotics, namely, ampicillin (amp). Absorption sampling was analyzed by UV-Vis spectrophotometer and the results indicate that the absorbance of the ampere increases to $85 \%$. The bond between these two is electrostatic bonding, which was confirmed by EDX analysis. Ultimately, this compound was used for the antibacterial process. In this case, the MNP- amp compound was added in a natural amount of $20 \mu \mathrm{l}$ a bacterial culture pattern overnight (In-vitro). The results showed that $95 \%$ of the bacteria were killed (confirmation of antibacterial properties of MNP). Therefore, it can be transmitted intentionally by controlling the magnetic field into living cells for the destruction of pathogenic bacteria.
\end{abstract}

\section{Key words}

magnetic nanoparticles; antibacterial property; silica-coated; electrostatic bonding; EDX analysis

\section{Introduction}

The medical use of magnetic powders dates back to ancient Greece and Rome, but as a systematic study of the biological and medical sciences of the 1970s, predicted that the particles used in the future would be vital to human health. Based on nanotechnology, a wide range of diagnostic and therapeutic applications are facilitated in diseases suchas cancer, heart disease and the nervous system. Magnetic nanoparticlesare used for targeted delivery of therapeutic agents and the common drug-based frequency between the ligand and the receptor is a magnet that involves intense exertion or certain magnetic absorption due to highperformance of intelligent control of the therapeutic factors in the desired tissue particle and is very important. Therefore, the magnetic carrier loses access to them [1].

Use of magnetic nanoparticles of magnetite has anti-bacterial properties

Magnetic nanoparticles are used in important biological applications, including separation and diagnosis of biomagnetic (cells, proteins, DNAs, nucleic acids, enzymes, microbes, etc.). For clinical diagnosis and treatment such as magnetic photography probes [2].
The label of nearly half a century of magnetic nanoparticles of magnetite as a strong choice has been applied therapeutically (in terms of laboratory) [3].Magnetic nanoparticles have a large surface that has high chemical activity. The size and surface of nanoparticles play an important role in their biological application. Therefore, it is unusual to increase the microbial resistance to healthy antibiotics protected by magnetic nanoparticles, reducing the size of magnetic nanoparticleswith certain chemical and physical agents that are of interest to scientists [4] and some advanced methods for controlling the size of magnetic nanoparticles is based on the proper design and functionality of their optimal performance and their control with wide application in the industry as an antibacterial in physics-biology. Active antibiotics on the surface of magnetic nanoparticles, due to their small particle size and high surface area, allow nanoparticles, viruses, fungi and membrane bacteria to interact. In this project, magnetic nanoparticles of $\mathrm{Fe}_{3} \mathrm{O}_{4} @ \mathrm{SiO}_{2}$ with a core/shell structure of $20 \mathrm{~nm}$ scale are provided. The nanoparticle surface has a high performance for absorbing biological molecules. Therefore, surface absorption of ampicillin (amp) antibiotics has reached a complete stabilization on its surface (scheme). 


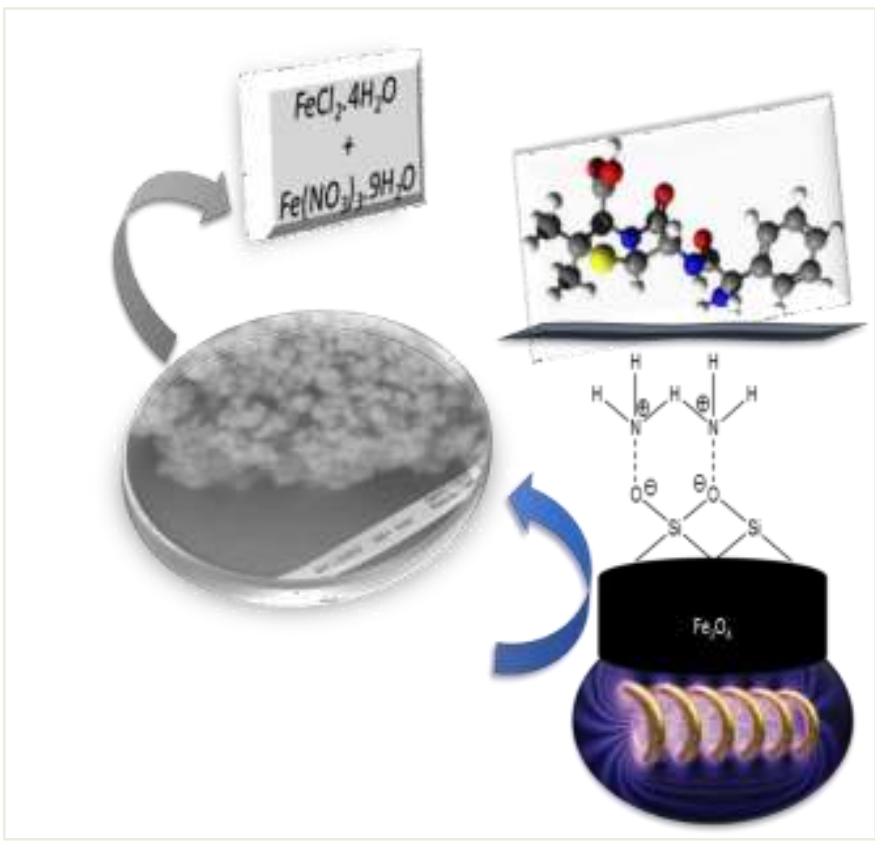

\section{Scheme}

A representation of ampicillin-loaded with magnetic nanoparticles

\section{Experimental}

Synthesis of silica-coated with $\mathrm{Fe}_{3} \mathrm{O}_{4}$ magnetic nanoparticles

Different mechanisms have been designed for the synthesis of hollow magnetite microspheres [5, 6-9]. Chemical Co-precipitation also one of the easiest and most convenient method of synthesis of magnetic nanoparticles with core/shell structure. The method is determined by the following formula $\mathrm{M}$ the same amount of iron salts (II).

$\mathrm{M}^{2+}+8 \mathrm{OH}^{-}+2 \mathrm{Fe}^{3+} \longrightarrow \mathrm{O}_{4}+4 \mathrm{H}_{2} \mathrm{O}$

Therefore, the sample salts containing iron ratios with a ratio of 1 to 2 $\left(150 \mathrm{mM} \mathrm{FeCl} l_{2} .4 \mathrm{H}_{2} \mathrm{O}\right.$ and $\left.300 \mathrm{mM} \mathrm{Fe}\left(\mathrm{NO}_{3}\right)_{3} .9 \mathrm{H}_{2} \mathrm{O}\right)$ were dissolved in distilled water.

\section{Results}

Synthesis and characterization of magnetic nanoparticle coated with silica

Chemical composition was used to prepare magnetic nanoparticles of magnetite $\left(\mathrm{Fe}_{3} \mathrm{O}_{4}\right)$ with metal oxide of $\mathrm{Fe}^{2+}, \mathrm{Fe}^{3+}$. After the preparation of magnetic nanoparticles, silica particles $\left(\mathrm{SiO}_{2}\right)$ were used in addition to the additional additive to prevent the oxidation of magnetic nanoparticles by air and also as a coating for increasing the functional level of nanoparticles for chemical reactions. The size of nanoparticles should be made at a scale of 1 to $100 \mathrm{~nm}$ to be useful for use in biomedical fields. To investigate and detect the structure of magnetic nanoparticles, a series of analyzes such as TEM, SEM, XRD, FT-IR, TGA, etc. are used. In this project, SEM analysis is used to stabilize the structure of magnetic nanoparticles. Analytical SEM provides analysis of a series of images of magnetic nanoparticles with core / shell structure. In the illustration, is the size of a nanoparticle that is $100 \mathrm{~nm}$, but for biomedical applications it should be $20 \mathrm{~nm}$. Thus, the synthesis of magnetic nanoparticles decreased by $20 \mathrm{~nm}$ (figure 1).

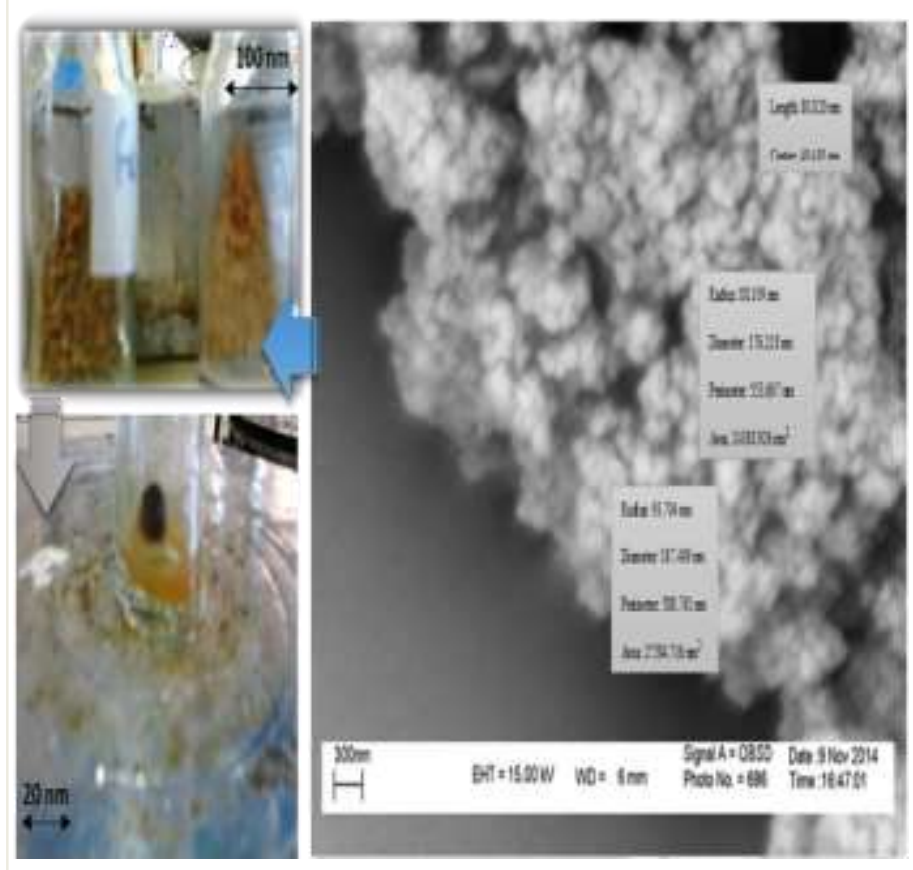

Figure 1.

SEM analysis of the morphology Core/Shell structure of magnetic nanoparticles

\section{Adsorption studies}

As the title of the project shows, I tested the stability of ampicillin antibiotics on $\mathrm{Fe}_{3} \mathrm{O}_{4} @ \mathrm{SiO}_{2}$ magnetic nanoparticles. Therefore, using the other researchers/comments and the results of my experiments, I found a fundamental result. As you know, magnetic nanoparticles and their magnetic properties can be controlled remotely with an external magnetic field. Previously, favorite biomolecules (amp) should be in response to MNPs, which should be a link between two. The most important thing is that the phenomenon of ampicillin absorption inMNPs is an electrostatic bond that was performed by EDX analysis and eventually proved to be bonded [11].

\section{Discussion}

Results of ampicillin loaded onto magnetic nanoparticles $\mathrm{Fe}_{3} \mathrm{O}_{4} @ \mathrm{SiO}_{2}$ by spectrophotometry

The absorption evaluation ampicillin on magnetic nanoparticles, the amount of $1 \mu \mathrm{g}$. $\mathrm{ml}^{-1}$ ampicillin is standard was developed by Bradford formula $\left(\mathrm{A}=2, \mathrm{C}=1 \mu \mathrm{g} \cdot \mathrm{ml}^{-1}\right)$. Which is defined as follows;

\section{1) $\mathbf{C}=\mathbf{5 0 . A ( O D ) / 1 0 0}$}

In formulas 50 and 100 there are fixed numbers and A (absorbance). The amount of A (OD) (absorbance value as well as by Beer lambert's law) [12] can be analyzed using spectrophotometric analysis. Beer Lambert's law states that part of the light after coloring with glass solution, absorption, and other passes. Continue with the device with a spectrophotometer, $20 \mathrm{mg}$ of magnetic nanoparticles added to $100 \mu \mathrm{g}$. $\mathrm{ml}^{-}$ 1 ampicillin solution Absorption of ampicillin was increased on nanoparticles (i.e. attracting top 85\%) (figure 2). 


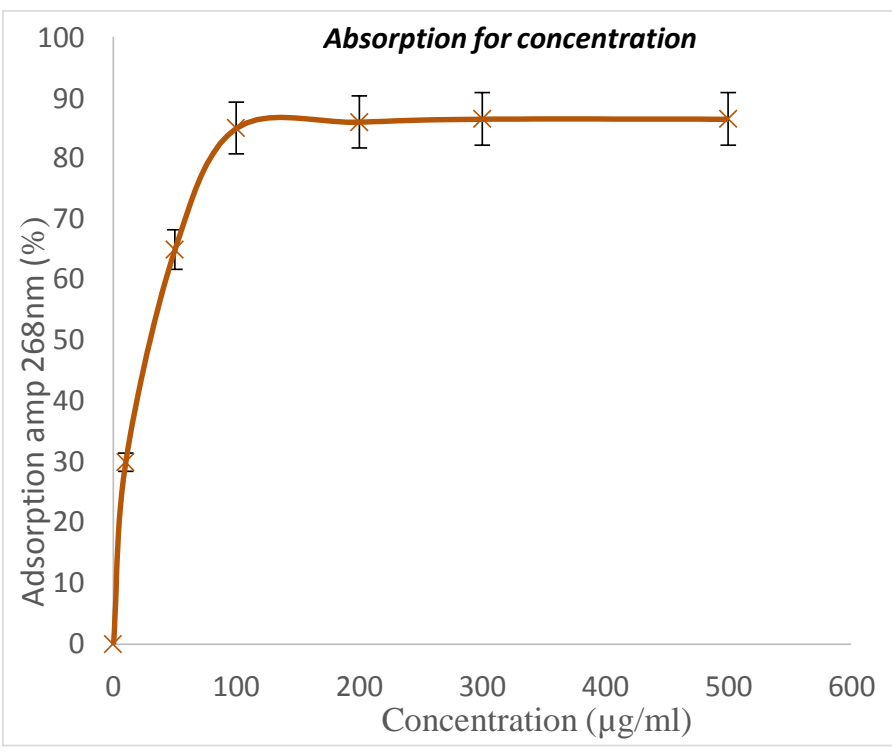

Figure 2.

Adsorption rate of ampicillin $(100 \mu \mathrm{g} / \mathrm{ml})$ in surface MNPs which it's for concentration.

Release of results and inhibition of bacterial growth by magnetic nanoparticles $\mathrm{Fe}_{3} \mathrm{O}_{4} @ \mathrm{SiO}_{2}$

Because the antibiotics used in this project as a model biological molecule are therefore only a sample of the bacteria can be an inhibitory effect of using magnetic nanoparticles $\mathrm{Fe}_{3} \mathrm{O}_{4} @ \mathrm{SiO}_{2}$ - ampicillin, on the growth of bacteria studied (Bacteria cultured in the lab, the bacteria are models). By comparing the results of spectrophotometry in the uptake and inhibit the growth of bacteria at a wavelength of $600 \mathrm{~nm}$ (absorption wavelength bacteria), was $95 \%$ and almost no trace of bacteria In-Vitro did not exist.

\section{Recovery of the retained ampicillin from the MNPs}

The results of the process of absorption and stabilization of (amp in MNPs) and release phase (delivery in bacteria), and that can be higher than the standard $24 \mathrm{hr}$ after absorption with concentration $(100 \mu \mathrm{g} / \mathrm{ml})$, that only $10 \%$ was lowed and $95 \%$ showed stable. So, it can be high performance of magnetic nanoparticles in the stabilization and consolidation ampicillin (figure 3).

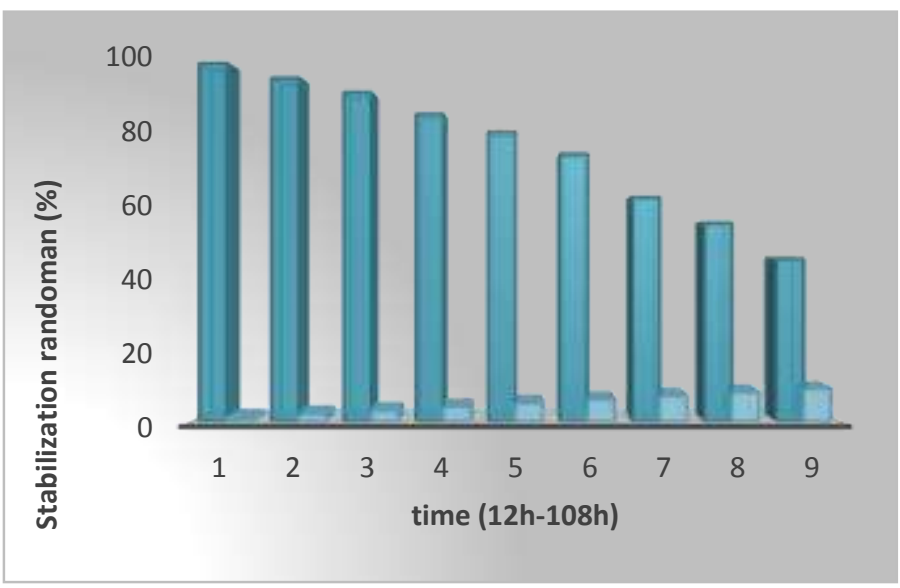

Figure 3.

The ampicillin resistance loaded MNPs over time
In this discussion, by $\mathrm{W} \%$ of elements perceived whichever were dependent to reactants of ampicillin and magnetic nanoparticles $\mathrm{Fe}_{3} \mathrm{O}_{4} @ \mathrm{SiO}_{2}$ and $\mathrm{EDX}$ analysis showed that both of the reactants bonded together been in the product. Also, elements of Fek $\alpha$ and Fek $\beta$

[10] with elements $\mathrm{Si}$ (with strong peak) and $\mathrm{O}$ are shown in $\mathrm{Fe}_{3} \mathrm{O}_{4} @ \mathrm{SiO}_{2}$ product. This analysis may be a demonstrative bond of between magnetic nanoparticles $\mathrm{Fe}_{3} \mathrm{O}_{4} @ \mathrm{SiO}_{2}$ and ampicillin. The results of the EDX analysis show that it may be stated this approaching is electrostatic bonding same.

\section{Conclusion}

The overall conclusion of this project, the nanoparticles prepared in terms of crystallography in good standing that has a particle size appropriate, then try using a functional magnetic nanoparticles level in the absorption of biomolecules (i.e. ampicillin). In addition to working on concentration suitable ampicillin to attract on nanoparticles was $\left(100 \mu \mathrm{g} . \mathrm{ml}^{-1}\right)$, by the electrostatic bond. Absorption of ampicillin was increased on nanoparticles (i.e. attracting top $85 \%$ ) as well as a stabilization time (108hr). Finally, experiments on bacteria were able to achieve satisfactory results achieved shown that magnetic nanoparticles with the presence of ampicillin powerful antibacterial lot (which amount to up 95\%), as well as MNPs alone, has antibacterial properties (the top 70\%), respectively. I hope my work can be suitable in the killing of diseases of bacteria on living cells.

\section{Abbreviations}

MNPs-amp: magnetic nanoparticles $\mathrm{Fe}_{3} \mathrm{O}_{4} @ \mathrm{SiO}_{2}$-ampicillin, SEM: Scanning Electron Microscope

FT-IR: Fourier Transform Infrared Spectroscopy, EDX: EnergyDispersive X-ray Spectroscopy

\section{Declarations}

\section{Authors' contributions}

The Supporting Information contains UV-Vis spectrophotometry absorption, Absorption time, Concentration absorption, EDX analysis, table of amounts adsorbed by bacteria and an SEM image of the magnetic nanoparticles and FT-IR analysis of agents group the silica layer and pictures of the influence of magnetic nanoparticles on bacterial growth and recovery graph nanoparticles.

\section{Authors' information (optional)}

This work was done by Mr. Mansour Binandeh. He has been able to graduate from the University of Maragheh in Iran, and this project has been fully and fully accomplished by himself.

\section{Acknowledgements}

All subjects received from various magazines in the field of nanotechnology with biology and chemistry. In furtherance of the goal of attracting the magnetic nanoparticles were Biomolecular antibiotics. I hope it been a day one of best research paper.

\section{References}

[1] Veiseh O, Gunn JW, Zhang M.(2010) Design and fabrication of magnetic nanoparticles for targeted drug delivery and imaging. Adv Drug Deliv Rev.3:284-286.

[2] Mornet S, Vasseur S, Garraset F, Duguet E. (2004) Magnetic nanoparticle design for medical diagnosis and therapy. Mater Chem.14:2161-2170.

[3] Gupta AK, Gupta M.(2005) Synthesis and surface engineering of iron oxide nanoparticles for biomedical applications. Biomater. 26: 3995-3999. 
[4] Pankhurst QA, Thanh NKT, Jones J, Dobson SK.(2009) Progress in applications of magnetic nanoparticles in biomedicine. J Phys D APPL PHYS. 42:22-27.

[5] Lu AH, Salabas EL, Schuth F. (2007) Magnetic nanoparticles; synthesis, protection, functionalization, and application. Angewandte Chemie Int Ed. 46:1222-1228.

[6] Laurent S, Forge D, Port M, Roch A, Robic C, Vander Elst L, Muller RN.(2008) Magnetic iron oxide nanoparticles: synthesis, stabilization, vectorization, physicochemical characterizations, and biological applications. Chem Rev. 108:2064-2068.

[7] Guan N, Wang Y, Sun D, Xu J.( 2009) A simple one-pot synthesis of single crystalline magnetite hollow spheres from a single iron precursor. Nanotechnology.20:105-603.

[8] Xi GC, Wang C, Wang X. (2008) The oriented; self-assembly of magnetic $\mathrm{Fe}_{3} \mathrm{O}_{4}$ nanoparticles into monodisperse microspheres and their use as substrates in the formation of $\mathrm{Fe}_{3} \mathrm{O}_{4}$ nanorods. Eur $\mathbf{J}$ Inorg Chem.3:425-429.
[9] Zeng SY, Tang KB, Li TW, Liang ZH, Wang D, Wang YK, Zhou W.(2007) Hematite hollow spindles and microspheres; selective synthesis, growth, mechanisms, and application in Li ion battery and water treatment. J Phys Chem C. 28:102-117.

[10] Ma M, Zhang Y, Yu W, Shen HY, Zhang HQ, GU N.(2003) Preparation and characterization of magnetite nanoparticles coated by amino silane. Coll Surf A Physicochem Eng Aspects.212:219221.

[11] Goldstein J, Newbury DE, Joy DC, Lyman CE, Echlin P, Lifshin E, Sawyer L, Michael JR.( 2003) Scanning Electron Microscopy and X-Ray Microanalysis. Springer Sci Busy Media NewYork.3:689-695.

[12] Ulrich J. Krull, Michael Thompson (Eds.), Encyclopedia of Physical science and Technology; Analytical Chemistry, 3rd Ed. 2001. Academic Press, ISBN 0-12-227410-5. 
